\title{
Surface Circulation in the Santa BARBARA CHANNEL
}

\author{
By M.C. Hendershott and C.D. Winant
}

$\mathrm{T}$ HE SANTA Barbara ChanNel is an elongated basin $\sim 100 \mathrm{~km}$ by $40 \mathrm{~km}$ lying between the California coast. where it trends westward from greater Los Angeles to Pt. Conception, and the east-west trending Channel Island chain of four offshore islands (San Miguel, Santa Rosa, Santa Cruz, and Anacapa) $~ 50 \mathrm{~km}$ offshore (Fig. 1). A 500-m deep basin occupies the western center of the channel, and narrow continental shelves with depths the order of $100 \mathrm{~m}$ border its northern and southern boundaries. The channel is separated from the Southern California Bight to the east by a sill 200 $\mathrm{m}$ deep between Anacapa and Port Hueneme. A sill $\sim 400 \mathrm{~m}$ deep between Pt. Conception and San Miguel Island separates the channel from the open ocean to the west. The Santa Maria Basin is around the corner, north of Pt. Arguello. The surface waters of the channel are primarily mixtures of warm and saline waters from the Southern California Bight with colder and fresher waters upwelled near and poleward of Pts. Conception and Arguello. The California current flows equatorward past the western mouth of the channel, but its greatest speeds and most pronounced water properties (higher temperatures and lower salinities than those of the upwelled water) are usually found several hundred kilometers to the west of the channel. Prevailing winds around Pt. Arguello are equatorward; strong and steady in the summer, weaker but far more variable in the winter. The channel itself is a relatively sheltered region. The transition from sheltered to exposed wind conditions occurs over a few kilometers in the western channel. These conditions all make the circulation in the channel and adjoining regions more complex - and less well understood-than anywhere else along the west coast of the United States.

At the same time, the Santa Barbara Channel and the Santa Maria Basin comprise a region of intense exploitation of known local oil and gas re-

M.C. Hendershott and C.D. Winant, Center for Coastal Studies. Scripps Institution of Oceanography, La Jolla, CA 92093-0209. USA serves. Particularly the Santa Maria Basin has the potential for discovery of important new reserves. The channel is additionally a major transportation lane for shipping to and from the greater Los Angeles area. The Minerals Management Service has the responsibility for long-term analysis of the oil spill risks associated with these activities as well as participating in planning for rapid response to individual oil spills. Consequently, in 1991, the Minerals Management Service entered into a cooperative agreement with the Scripps Institution of Oceanography to carry out a detailed study of the surface circulation of the channel and Santa Maria Basin region. The goals of this study are 1) to describe and scientifically understand the complex flow in the channel and Santa Maria Basin region with emphasis on the surface circulation, and 2) to summarize the description and understanding in a manner useful to Minerals Management Service analysts, whose responsibility is oil spill risk analysis. The second goal focuses the work more closely on the documentation of surface parcel trajectories than has been usual in previous studies of coastal circulation along the California coast.

The project consists of a systematic analysis of historical data, execution of new fieldwork, and data analysis and synthesis in support of the two major goals outlined above. An important part of the data management has been the construction and maintenance of an extensive data bank that is generally accessible over the Internet, and that will ultimately contain the new data collected during the fieldwork as well as the historical data.

The earliest surveys (Sverdrup and Fleming, 1941 ) outlined the general pattern of $0 / 500 \mathrm{~m}$ circulation in the greater Southern California Bight. The California Current has a strong shoreward component at about the latitude of the US-Mexican border; near the coast this flow bifurcates, and the poleward component flows alongshore toward the eastern mouth of the Santa Barbara Channel. Subsequent California Cooperative Fisheries Investigation (CalCOFI) data both filled in spatial detail and delineated a strong seasonal cycle, with poleward flow in the vicinity of the eastern mouth
$T_{\text {he }}$ of a systematic analysis of historical data, execution of new fieldwork, and data analysis and synthesis . . . 
of the channel year round except for February through April (Reid, 1965; Lynn and Simpson, 1987). But the CalCOFI data stations are too widely spaced to resolve the flow within the channel.

Motivated by the 1969 Santa Barbara Channel oil spill, Kolpack (1971) carried out three hydrographic cruises during May, August, and December, 1969, as well as eight drift card surveys of the surface circulation. The drift card surveys resolved a counterclockwise circulation in the western half of the channel and a northwesterly flowing current in the eastern part. Kolpack (1971) stated that "The zone of interaction between these two currents occurs in the area between Santa Barbara and Santa Cruz Island."

In 1983 the Organization of Persistent Upwelling Study (OPUS) documented new facts about the wind and flow fields in the vicinity of Pt. Conception. Aircraft observations (Brink et al., 1984) revealed strong winds off Pt. Conception that were consistently equatorward, but became much more gentle in a sheltered area east of Pt. Conception. Vigorous upwelling occurs between Pts. Arguello and Conception as well as along the coast north of Pt. Arguello (Brink et al., 1984; Atkinson et al., 1986); hydrographic observations reported by Atkinson et al. (1986) documented variability of the direction of the upwelling plume between southwestward and southeastward. The plume frequently entered the Santa Barbara Channel, but its direction was not obviously related to local winds. Time series of currents and temperature were collected at a number of mooring sites around the periphery of the channel and near Pt. Conception during a 57-day spring and summer period of 1983 (Brink and Muench, 1986). At 1983 mooring C1, located roughly halfway along a line between Pt. Conception and Pt. Arguello, there were clear surface flow counterparts of wind events at NDBC Buoy 11 moored $\sim 30 \mathrm{~km}$ north of the latitude of Pt. Conception along the $200-\mathrm{m}$ isobath, but about midway through the observing period this correspondence vanished (Brink and Muench, 1986). There was no such a correspondence between winds and currents at any other moorings, including the very nearby mooring P2 $\sim 10 \mathrm{~km}$ south of Pt. Conception. These results were in marked contrast with those of the then recently concluded CODE experiment (Winant et al., 1987).

In 1984 the Minerals Management Service carried out a year-long study (Gunn et al., 1987) designed primarily to provide boundary conditions for numerical modeling of the circulation within the Santa Barbara Channel. The mean flow at the east mouth was poleward, at the western mouth there was westward flow past Pt. Conception and eastward flow past San Miguel Island. The fluctuating western mouth flow was dominated by transient events of enhanced cyclonicity, and drifters

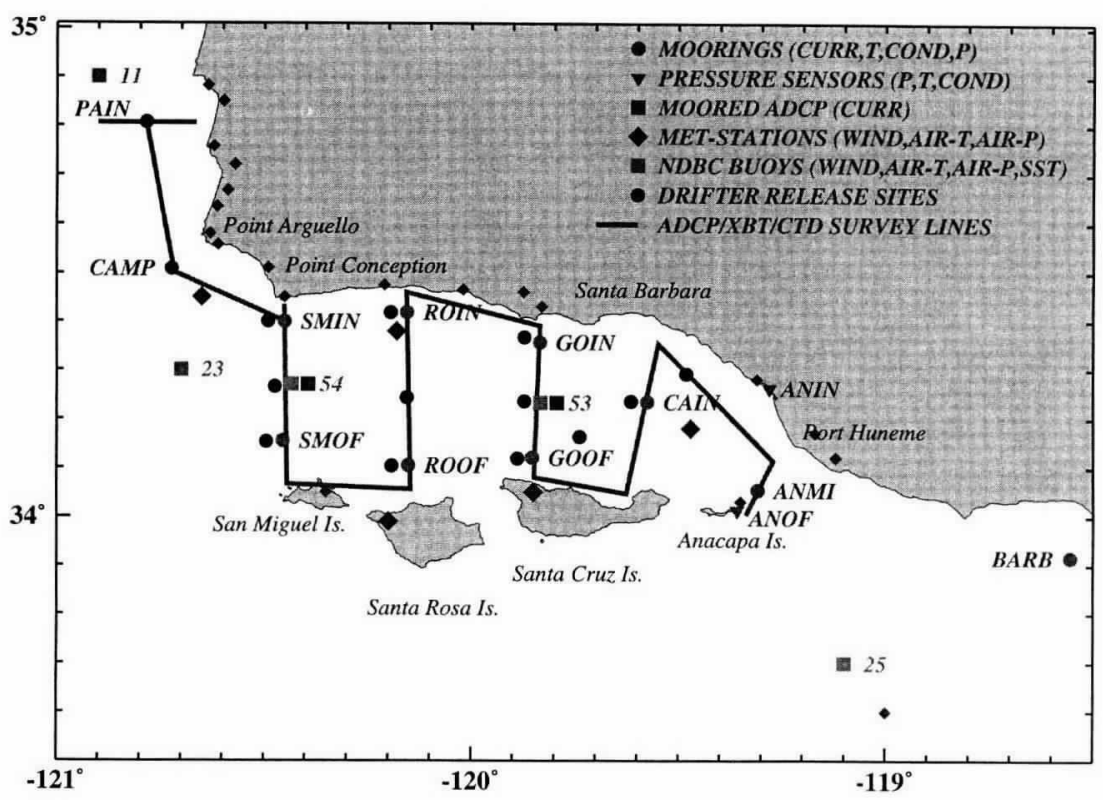

Fig. 1: Place names, mooring locations (lightly shaded solid circles) at which currents, temperatures and conductivities at 5 and $45 \mathrm{~m}$ (and $100 \mathrm{~m}$ at ANMI), temperatures at 1,25, and $65 \mathrm{~m}$, and pressure, temperature, and conductivity at anchor depth of $100 \mathrm{~m}$ (200 $\mathrm{m}$ at ANMI) are recorded; anchor locations (lightly shaded triangles) at which pressure, temperature, and conductivity are recorded at anchor depth $(10 \mathrm{~m})$, downward-looking acoustic Doppler current profiler mooring locations (lightly shaded squares), NDBC meteorological buoy locations (heavily shaded squares), oil platform and coastal meteorological station locations (lightly shaded diamonds), drifter release sites (heavily shaded solid circles).

correspondingly traced out counterclockwise paths in the western channel. The correlation between flow and winds in the channel continued to be much lower than in the CODE experiment. Lagerloef and Bernstein (1988) analyzed a year of Advanced Very High Resolution Radiometer (AVHRR) images approximating sea surface temperature in the channel during the 1984 Minerals Management Service Study. The dominant mode of sea surface temperature variation was seasonal modulation of the strength of the thermal front between warm water from the Southern California Bight and cold water along the Channel Islands. The images also suggested the presence of counterclockwise eddies in the channel, usually persisting for many days and drifting slowly westward.

The present program of fieldwork was designed to complement the 1984 study by providing more detail in the interior of the channel and near the surface. Deployment began in 1992, much of the moored array shown in Figure 1 has been in place for $>3$ years. Meteorological observations are variously acquired from: National Data Buoy Center (NDBC) buoys moored both inside the SBC (buoys 53 and 54) and at either end of the channel (buoys 23 and 25), fixed stations on the Channel Islands and on oil platforms, and land stations maintained by various air pollution control agencies. Uninter-
The fluctuating

western mouth flow

was dominated by

transient events of

enhanced cyclonicity,

and drifters corre-

spondingly traced out

counterclockwise

paths in the western

channel. 
rupted series of currents, temperature, salinity, and bottom pressure are collected at the mooring locations shown in Figure 1. Most moorings are in water $100 \mathrm{~m}$ deep, either on the continental shelf adjacent to the coast or close to the Channel Islands, and are instrumented to measure currents, temperatures, and salinities 5 and $45 \mathrm{~m}$ beneath the surface, temperature at the additional depths of 1 , 25 , and $65 \mathrm{~m}$, and temperature, salinity, and bottom pressure at the anchor (nominally at $100 \mathrm{~m}$ depth). One mooring (ANMI) is located at the eastern sill in water $200 \mathrm{~m}$ deep, and it has an additional current meter (with temperature and salinity sensors) at $100 \mathrm{~m}$. Data from the 5-m instruments are routinely telemetered via the Argos system. Several moorings (ANIN, ANOF) are in very shallow water; they are instrumented only for bottom temperature, salinity, and pressure. CAMP was maintained as part of a separate study (Hamilton, 1994). Each NDBC buoy located in the channel (53 and 54) is equipped with water temperature sensors at $1 \mathrm{~m}$ depth and with a downward-looking $75-\mathrm{kHz}$ acoustic Doppler current profiler. The most direct information about where the surface circulation carries surface parcels comes from the trajectories of drifters designed to follow parcels as they move in the surface circulation. For this purpose, the surface-parcel-following low

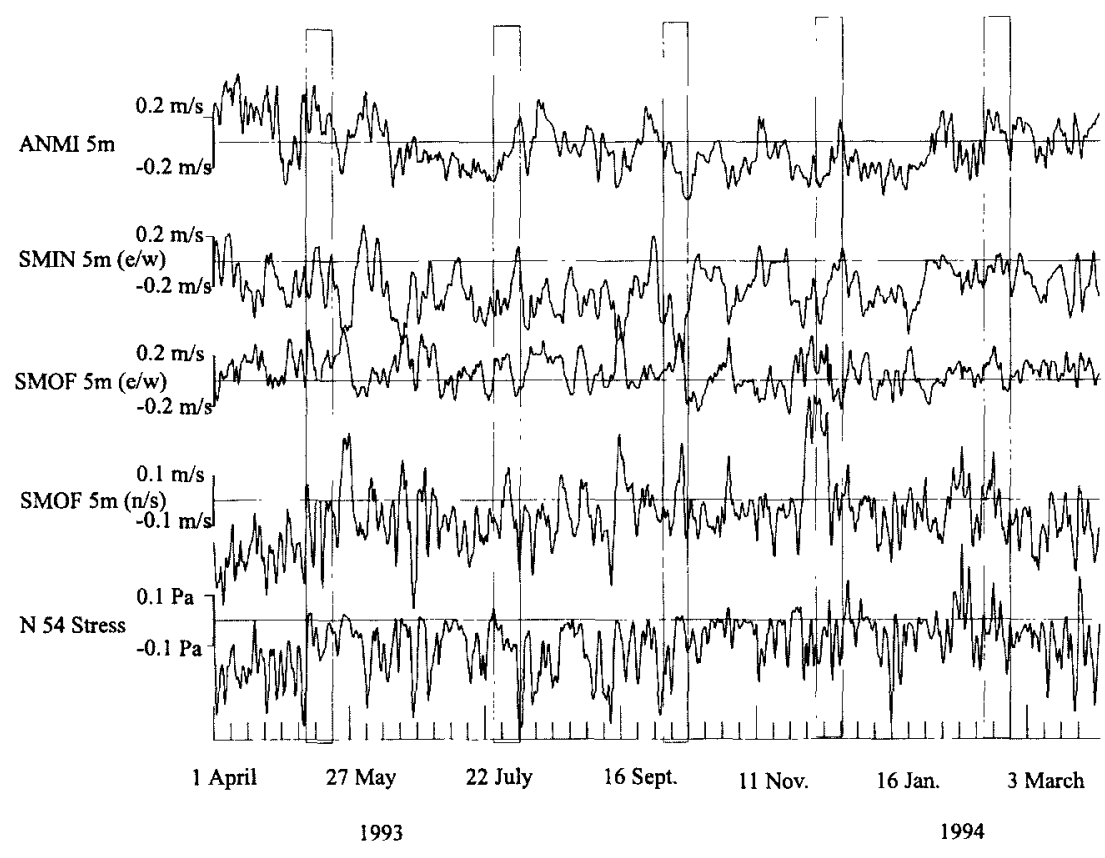

Fig. 2: Major axis (along $\left.136^{\circ}\right)$ subtidal currents $(\mathrm{m} / \mathrm{s})$ at $5 \mathrm{~m}$ depth at eastern mouth (ANMI); east-west subtidal currents $(\mathrm{m} / \mathrm{s})$ at $5 \mathrm{~m}$ depth at western mouth near Pt. Conception (SMIN); east-west subtidal currents $(\mathrm{m} / \mathrm{s})$ at $5 \mathrm{~m}$ depth at western mouth near San Miguel Island (SMOF); north-south subtidal currents $(\mathrm{m} / \mathrm{s})$ at $5 \mathrm{~m}$ depth near San Miguel Island (SMOF); and major axis $\left(313^{\circ}\right)$ wind $(\mathrm{m} / \mathrm{s})$ at NDBC meteorological buoy 54. Time ticks are 1 wh apart. Vertical lines indicate 1st 10 days of May, July, September, and December 1993 and February 1994 drifter deployments. windage drifter design of Davis (1985) was internally modified to be tracked by the Argos system and to measure and transmit surface $(1 \mathrm{~m})$ temperature. At least 12 drifters are released every 2 mo in the pattern shown in Figure 1 and tracked over a 40-day period. The Santa Barbara Channel and Santa Maria Basin region is surveyed twice a year during mooring maintenance cruises. A fish instrumented with a downward-looking $150-\mathrm{kHz}$ acoustic Doppler current profiler, an upward-looking 1.2$\mathrm{MHz}$ acoustic Doppler current profiler, and a conductivity-temperature-depth (CTD) profiler (Münchow et al., 1995) is towed behind the survey vessel at a depth of 16-20 m along the tracks shown in Figure 1. The absolute velocity of the fish is obtained, with comparable accuracy, either from the downward-looking acoustic Doppler current profiler when the bottom is within acoustic range. or from differential Global Position System fixes. Expendable bathythermograph probes (XBTs) are deployed while the fish is being towed. On most cruises, major parts of the survey path are reoccupied as CTD lines. Advanced very high resolution radiometer (AVHRR) NOAA satellite images of the sea surface are obtained several times daily. This report describes the most important features of the emerging picture of the surface circulation in the Santa Barbara Channel.

\section{The Surface Circulation}

To concisely illustrate the salient features of the surface circulation, a single year (1 April 1993 through 31 March 1994) of selected velocity records at moorings in the eastern mouth of the Santa Barbara Channel and in the north and south ends of the western mouth (ANMI. SMIN, and SMOF, respectively) has been plotted in Figure 2. whereas Figures 3-5 show drifter displacements superposed on contemporaneous AVHRR images for the three drifter deployments made in May, 1993, in October, 1993, and in February, 1994.

\section{Flow Through the Eastern Mouth}

In annual mean, surface flow at the eastern mouth is poleward into the channel from the Southern California Bight. This was also true during the 1983 OPUS Study (Brink and Muench, 1986) and in the 1984 Minerals Management Service Study (Gunn et al., 1987). The east mouth flow, however, reverses seasonally, being generally poleward from July through January and generally equatorward from February through June during the year plotted in Figure 2. The 0/500-m flow in the CalCOFI data for this region (Lynn and Simpson, 1987) shows similar seasonal variation, but there was no seasonal reversal of the east mouth flow at $30 \mathrm{~m}$ during the 1984 Minerals Management Study (Gunn et al., 1987).

Superposed on this seasonally varying east mouth surface flow are fluctuations lasting days to weeks. 


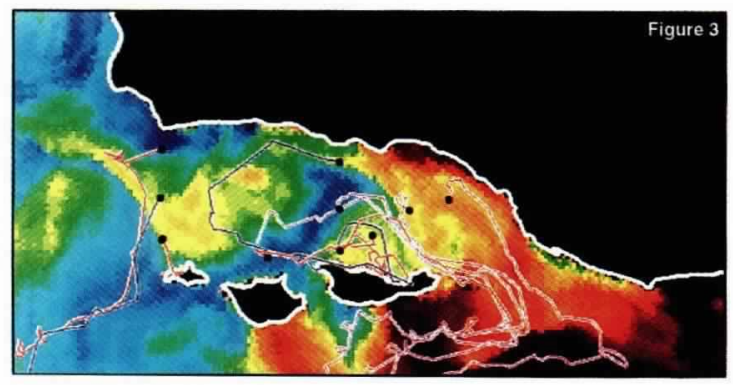

Fig. 3: Seasurface temperature 12 May 1993 at 2329 GMT together with tracks of drifters released 11 and 12 May 1993 (earliest deployment of Fig. 2). Temperature range is $10.9^{\circ} \mathrm{C}$ (dark blue) to $15.5^{\circ} \mathrm{C}$ (dark red).

They are strong enough to reverse the subtidal surface flow through the eastern mouth many times during the year plotted. The resulting episodes of either reversed or unusually strong flow last days to weeks. When they coincide with drifter releases made during the poleward season, the drifters exit the Santa Barbara Channel equatorward into the Southern California Bight (e.g., the May 1993 and February 1994 releases, Figs. 3 and 5). There is no obvious correlation between these events and either local winds or the much stronger winds in the vicinity of Pt. Conception (Fig. 2).

The direction of 5-m flow through the eastern mouth allows all drifter deployments to date to be classified a priori as either "exit east" (e.g., the February 1994 deployment of Fig. 5) or "exit west" (e.g., the October 1993 deployment of Fig. 4). The important implication is that the direction of 5-m flow at ANMI consistently identifies the overall sense of surface parcel drift into or out of the Santa Barbara Channel.

\section{Flow Through the Western Mouth}

In annual mean the surface flow is poleward (westward) along the north shore of the channel, and equatorward (eastward) along the north side of the Channel Islands. This was also true during

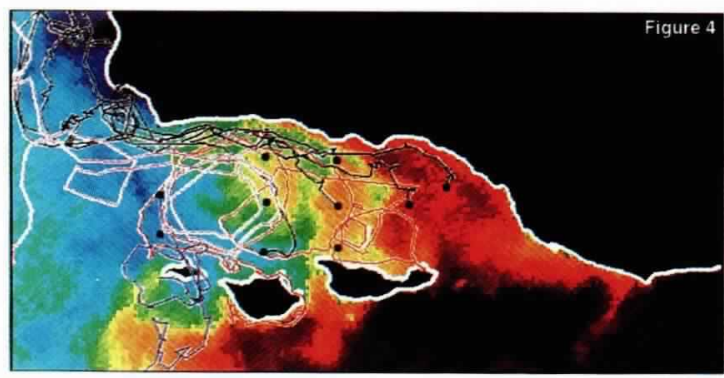

Fig. 4: Seasurface temperature 6 October 1993 at 0242 GMT together with tracks of drifters released on that day (3rd deployment of Fig. 2). Temperature range is $11.9^{\circ} \mathrm{C}$ (dark blue) to $16.5^{\circ} \mathrm{C}$ (dark red).

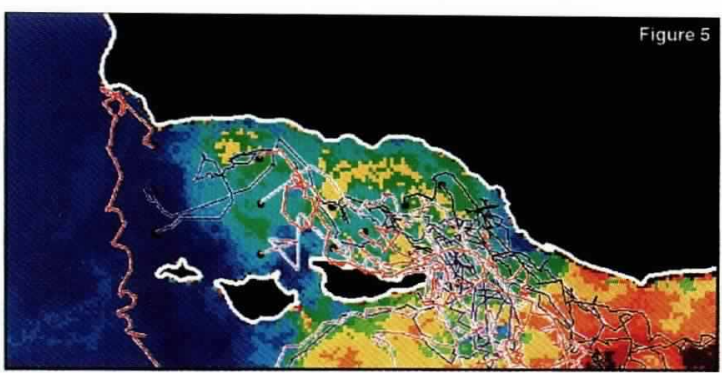

Fig. 5: Seasurface temperature 14 February 1994 at 2355 GMT together with tracks of drifters released the next day (last deployment of Fig. 2). Temperature range is $13.5^{\circ} \mathrm{C}$ (dark blue) to $14.8^{\circ} \mathrm{C}$ (dark red); some detail is obscured by low level haze and clouds in the western Santa Barbara Channel.

the 1983 OPUS Study (Brink and Muench, 1986) and in the 1984 Minerals Management Service Study (Gunn et al., 1987). The magnitude of the resulting east-west velocity difference across the western mouth (from Pt. Conception to San Miguel Island) varied seasonally in the year plotted in Figure 2, being greatest from May through January and smallest from February through April. The period during which the difference is greatest coincided roughly with the period of strong poleward flow through the eastern mouth, but it is difficult to claim that the two seasonal cycles are identical because we have so few years of data.

Superposed on this seasonally varying western mouth shear are fluctuations lasting weeks. They are visible in Figure 2 as strongly anticorrelated fluctuations of east-west 5-m velocity at the north and south ends of the western mouth. They are strongest during the season of strongest monthly mean western mouth shear (June through September), when they recur remarkably regularly and are occasionally even able to reverse the normally westward flow in the vicinity of Pt. Conception. They are virtually absent during the season of weakest shear (January through April). As Figure 2 makes clear, they are not strongly correlated with winds in the vicinity of Pt. Conception. Similar fluctuations were also observed in the 1984 Minerals Management Service Study (Gunn et al., 1987), but their intensity did not show an obvious seasonal cycle.

Events in the 5-m east-west flow at Pt. Conception (SMIN) are generally in fairly good visual correspondence with events in the 5-m eastern mouth flow at ANMI. It is noteworthy that this correspondence is least apparent during the time (June through September) of greatest monthly mean shear across the western mouth.

Although the direct influence of winds is difficult to discern in the individual time series of 5-m east-west currents plotted in Figure 2, north-south currents at SMOF near San Miguel 
Island are visibly correlated with winds at nearby meteorological buoy NDBC 54 (and hence with winds in the Santa Maria Basin and offshore of Pt. Conception) throughout the entire year plotted in that figure. This is the strongest relationship between local currents and local winds in all of our observations. It is noteworthy that there is no similar relationship between winds and 45-m currents.

\section{Upwelling and the Fate of Upwelled Water}

Winds along the coast north of Pt. Arguello are almost always upwelling favorable. They are strongest and steadiest in the summer, but much more variable in the winter due to passing storms (Dorman and Winant, 1995). Upwelling episodes along the coast north of Pt. Arguello are abundantly evident throughout the year on AVHRR images of the region. upwelling also very frequently occurs at Pt. Conception and sometimes spreads 10-20 km eastward along the coast from Pt. Conception. The correspondence between wind events and cold temperatures at the north end of the western mouth is, however, not perfect, at least in part because strong poleward (westward) flow through the eastern mouth can bring relatively warm Southern California Bight water to and even past Pt. Conception.

On AVHRR images the upwelled water usually extends away from the Pt. Arguello-Pt. Conception region as a cold plume that sometimes points directly southward toward San Miguel Island, but more frequently bows out toward the west (apparently under the influence of poleward flow exiting the channel through the north side of the western mouth) before ultimately returning to the channel through the south end of the western mouth; water inside the channel along the north side of the Channel Islands is thus often contiguous with water upwelled in the vicinity of Pt. Conception. This surface Channel Island shelf water is generally cold relative to the water along the north coast of the channel, and generally flows toward the east from San Miguel Island toward Santa Rosa Island and sometimes onward toward Santa Cruz Island.

On some AVHRR images the upwelling plume originating in the Pt. Arguello-Pt. Conception region has actually been broken by warm water exiting the channel and/or distorted by flow structures incident on the western mouth from the open ocean to the west. Both processes appear to be important during the May 1993 drifter deployment (Fig. 3); the drifter released near Pt. Conception first moves nearly westward with the warm water exiting the channel through the northern part of the western mouth, but then becomes caught up in the southeastward limb of the termination of a jet that comes toward Pt. Conception from the southwest and bifurcates into northwestward and a southeastward limbs $\sim 20 \mathrm{~km}$ southwest of the re- gion between Pt. Conception and Pt. Arguello. On the single image of Figure 3, the jet itself is not obvious, but the southeastward limb of its termination is clearly visible; the interpretation of this feature as a terminating jet is based on the evolution of sea surface temperature in this region over several days of images including the image of Figure 3 .

\section{Eddy Motion in the Western Santa Barbara Channel}

To the extent that the strong fluctuations in the difference between east-west velocity across the western mouth discussed above and documented in Figure 2 do not appear as flow reversals at the eastern mouth mooring. they must point to significant transient recirculation, within the channel, of fluid entering the channel through the western mouth. The clearest description of the resulting flow is provided by the drifters and AVHRR images. Particularly, the drifter trajectories often show the presence of a strong counterclockwise eddy that fills the entire western half of the channel; the October 1993 deployment (Fig. 4) is a typical example.

In the entirety of our data, this western channel eddy is most pronounced during those deployments made during the months (June to September) when the shear across the western mouth is strongest, and is then one of the most important features of the surface circulation for understanding the pattern of drifter displacements. It is almost completely absent during deployments made during the months (January through April) when the shear across the western mouth is small. Thus Figure 5 shows drifter trajectories for the February 1994 deployment during which, from Figure 2, the shear across the western mouth is minimal; there is no visible evidence of counterclockwise drifter motion in the western half of the channel.

The east-west velocity difference across the western mouth was larger both just before the May 1993 deployment than during it (Fig. 2). The surface temperature field (Fig. 3) during that deployment thus continues to suggest counterclockwise flow in the western channel. Only one of the drifters moves correspondingly, but this is in part because the deployment did not fully sample the western half of the channel; drifters released in the western mouth either beached on San Miguel Island or, in the case of the drifter initially released near Pt. Conception, followed the warm water moving westward out of the channel. The eastwest velocity difference across the western mouth again increased just after the end of the deployment; correspondingly a single drifter released in the western channel at the end of the deployment (but not plotted on Fig. 5) moved gradually westward executing a series of very tight counterclockwise loops. 
The presence or absence of a strong cross channel difference in east-west flow across the western mouth of the channel allows all drifter deployments to date to be classified a priori as either "strongly counterclockwise in the western channel" (e.g., the October 1993 deployment of Fig. 4) or "not clearly clockwise/counterclockwise in the western channel" (e.g., the February 1994 deployment of Fig. 5). The important implication is that the records of flow at SMIN and SMOF consistently identify the overall sense of surface parcel drift within the western channel.

\section{The Santa Rosa Cold Squirt}

The cold water along the north side of the Channel Islands rarely reaches the eastern mouth of the channel. Even at times when the flow through the eastern mouth is equatorward (eastward), the cold water instead usually leaves the Channel Islands in a "cold squirt" pointed roughly northeastward from the northernmost point of Santa Rosa Island. Kolpack (1971) had noted such a feature in his CTD survey surface temperature maps.

This Santa Rosa cold squirt is a relatively narrow (order $10-\mathrm{km}$ width) feature on many AVHRR images. It is most clearly visible on the AVHRR image of Figure 3. The northeastward flow associated with it generally bifurcates a few tens of kilometers offshore somewhere between Pt. Hueneme and Santa Barbara, so that there is frequently a stagnation point in drifter displacements there. On some AVHRR images (e.g., Fig. 3 ), this bifurcation of the cold squirt has the frequently observed "hammerhead" structure. Some part of the flow turns westward to join the westward flow of warm water that generally prevails along the north coast of the channel, and the rest turns southeastward.

The southeastward limb of the bifurcated Santa Rosa squirt often carries drifters toward Santa Cruz Island. Some of them beach there, but many more hesitate and move irregularly in the vicinity of the embayment comprising the eastern half of the northern coast of Santa Cruz Island for days, after which their decision to ultimately move eastward or westward seems to depend on the strength and direction of the flow through the eastern mouth. During the May 1993 deployment summarized in Figure 3, a number of drifters followed the southeastward limb into the embayment, and three went aground there.

\section{Waters Exiting the Santa Barbara Channel}

When flow through the channel is equatorward, the waters exiting the eastern mouth of the channel generally turn clockwise and ultimately move westward along the south side of the Channel Islands. This tendency is very clear in the drifter paths of Figure 5. Correspondingly, a plume of cold water protrudes deep into the Southern Cali- fornia Bight from the eastern mouth of the channel. Poleward moving warm water from the Southern California Bight veers westward when it meets this cold plume and flows westward along the south side of the Channel Islands. The February 1994 deployment of Figure 5 is unusual in the extent to which many drifters penetrate far into the Southern California Bight.

The poleward flow that usually exits the channel in the vicinity of Pts. Conception and Arguello often follows the coast northward, but it sometimes continues westward as a concentrated jet. Thus Figure 4 shows drifters leaving the channel through the northern part of the western mouth and rounding Pts. Conception and Arguello to move poleward along the coast. The May 1993 deployment of Figure 3 was preceded by an episode of poleward flow at ANMI with simultaneous strongly counterclockwise flow in the western Santa Barbara Channel. Winds were strongly upwelling favorable right up to the start of the deployment and then dropped abruptly (Fig. 2). Our interpretation of Figure 3 is thus that strong upwelling near and even east of Pt. Conception has interrupted the earlier westward flow of warm water along the northern coast of the channel past Pt. Conception.

\section{Discussion}

The salient features of the surface circulation as delineated by moored 5-m currents, drifter tracks, and AVHRR images are as follows.

- In monthly mean, subtidal flow through the Santa Barbara Channel as monitored at the narrow eastern mouth is usually poleward except in the wintertime. Fluctuations sufficiently large to reverse the instantaneous subtidal flow for days to weeks occur year round.

- Counterclockwise recirculation occurs in the western channel. In monthly mean. it is strongest spring through autumn, with flow past Pt. Conception almost always poleward (westward) and western mouth flow past San Miguel Island almost always equatorward (eastward).

- Strong upwelling can occur near Pts. Conception and Arguello throughout the year, the upwelled water frequently enters the channel eastward along the Channel Islands as part of the recirculation.

- Episodes of vigorous counterclockwise eddy motion over time scales the order of weeks are frequent, recur remarkably regularly during spring and summer in the western half of the channel, and are much less energetic during the winter.

- Transport of cold water northward away from the Channel Islands usually occurs in a jet that leaves the islands in the vicinity of Santa Rosa Island. This jet bifurcates into westward and eastward flowing currents a few tens of kilometers offshore of the coast between Santa Barbara and Pt. Hueneme.
When flow through

the channel is equa-

torward, the waters

exiting the eastern

mouth of the channel

generally turn clock-

wise and ultimately

move westward along

the south side of the

Channel Islands. 

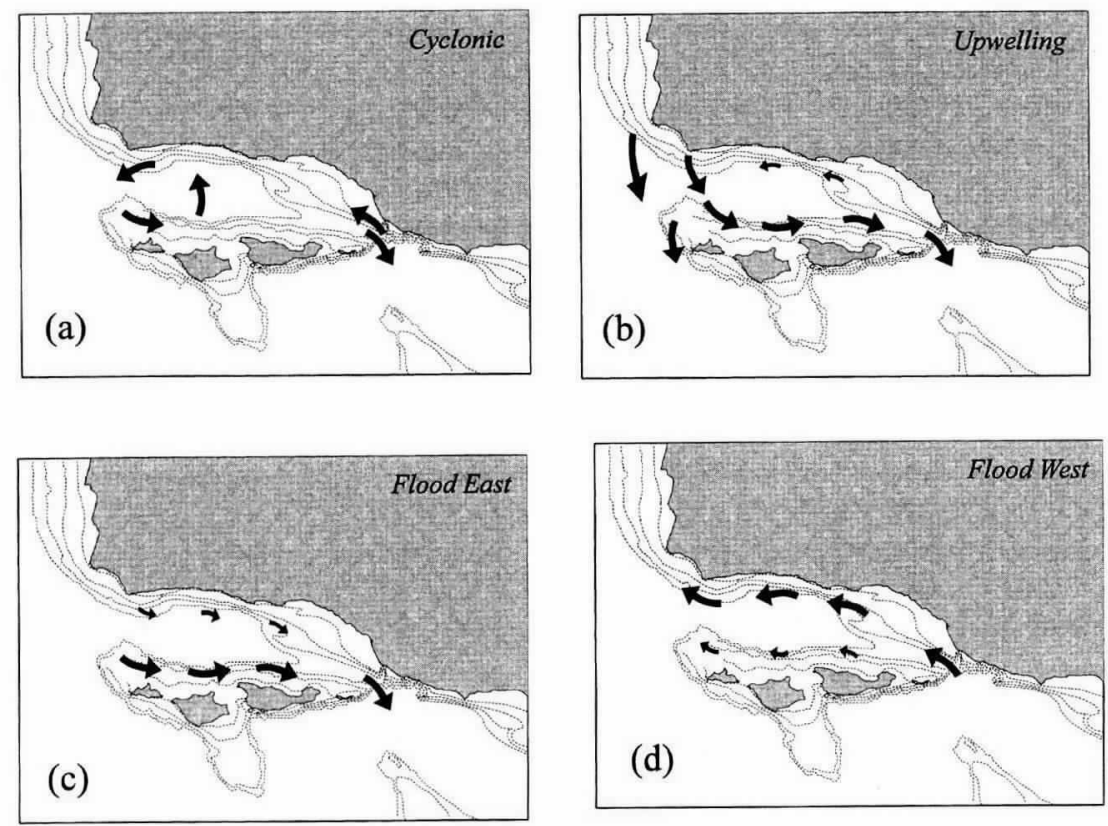

Fig. 6: Synoptic states of surface circulation in the Santa Barbara Channel.

- The poleward flow that usually exits the channel in the vicinity of Pts. Conception and Arguello often follows the coast northward, but during episodes of strong upwelling continues westward as a concentrated jet. When flow through the channel is equatorward, waters exiting the eastern mouth of the channel generally turn clockwise to ultimately flow westward along the south side of the Channel Islands.

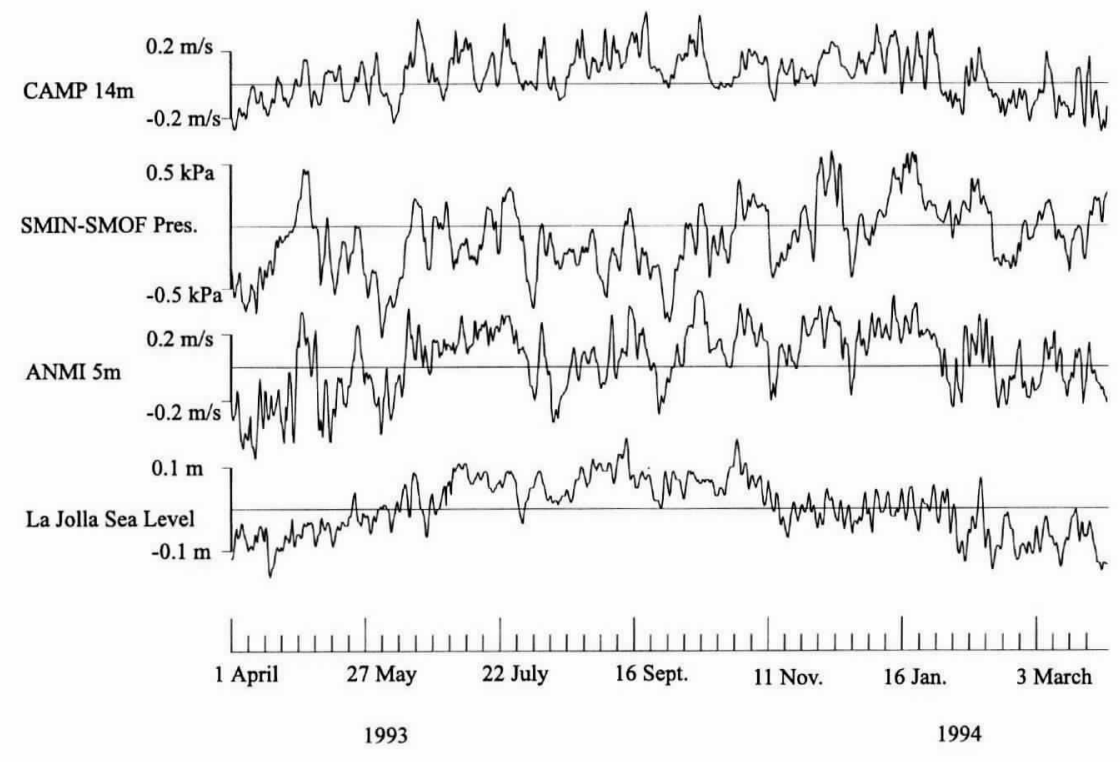

Fig. 7: Major axis $\left(313^{\circ}\right) 14-\mathrm{m}$ subtidal flow $(\mathrm{m} / \mathrm{s})$ at mooring $20 \mathrm{~km}$ southwest of Pt. Arguello (CAMP); subtidal synthetic surface north-south pressure difference $(\mathrm{kPa})$ across western mouth of $S B C(\mathrm{mb})$; 5- $\mathrm{m}$ subtidal major axis $\left(316^{\circ}\right)$ flow $(\mathrm{m} / \mathrm{s})$ at eastern mouth (ANMI) of Santa Barbara Channel $(\mathrm{cm} / \mathrm{s})$; and subtidal sealevel at La Jolla $(\mathrm{m})$. Time ticks are 1 wk apart. Positive values of all plotted series are associated with poleward flow.
The most frequently occurring combinations of the various features of the surface flow that are described above may be summarized in terms of a few synoptic patterns. These are sketched in Figure 6. They are the conceptual analogues of the atmospheric synoptic states to which a meteorologist asked for a summary of weather over the Santa Barbara Channel might refer, saying for example that the situation is a Santa Ana or is dominated by the Catalina eddy. The finding that the direction of 5-m flow at ANMI allows all drifter deployments to be classified a priori as either "exit east" or "exit west" gives rise to identification of the two corresponding synoptic states "flood east" and "flood west" shown in Figure 6. Likewise, the correspondence between the presence of a strong cross channel difference in eastwest flow across the western mouth of the channel and the occurrence of strong counterclockwise eddy motion during individual drifter deployments gives rise to identification of the synoptic state labeled "cyclonic." Finally, the observed tendency of surface flow in the vicinity of the western mouth to be downwind during times of strong upwelling-favorable winds with the concomitant entry of cold water into the channel along the northern side of the Channel Islands gives rise to identification of the synoptic stated labeled "upwelling."

Flood east and flood west differ in more than the direction of transport through the channel; during flood west the strongest currents are generally along the northern coast of the channel, whereas during flood east they are along the north side of the channel islands. The upwelling state differs from flood east both in the tendency of drifters in the western mouth to move downwind (toward the southeast) and the near stagnation of flow along the northern coast of the channel. Flood east is usually of short duration compared with upwelling. The cyclonic state may be superposed on any of these states, although only rarely on upwelling. Although the synoptic states are more subjectively defined than, for example, empirical orthogonal functions, they have been found useful in tasks ranging from screening telemetered or recovered data for possible instrument malfunction to answering real time requests for information about currents in the channel.

The foregoing description of surface flow in the channel says little about what may drive the flow. Detailed identification of forcing agents must await quantitative analysis, but even at this stage several facts are clear. The first point is that local winds are a good deal less important in determining the flow in the channel than elsewhere along the west coast of the United States. This situation is in marked contrast with, e.g., the CODE observations (Winant et al., 1987), where there was virtually one to one correspondence between fluctuations in alongshore wind and flow. 
The second point is that an appreciable part of the variance in the channel flow appears to reflect flow fluctuations at larger-than-Santa Barbara Channel scales. The near coincidence of seasonal cycles in flow through the channel (as monitored by flow through the narrow eastern mouth) and the 0/500-m flow in the CalCOFI data for this region (Lynn and Simpson, 1987) suggests that this is true at seasonal time scales. The data plotted in Figure 7 suggest that influence of larger-thanchannel scales may persist at time scales of days to weeks. Figure 7 compares the 5-m principal axis flow through the eastern mouth with the north-south synthetic subsurface pressure difference across the western mouth; the event-by-event coincidence indicates that the eastern mouth mooring captures much of the variance at periods of days to weeks in the channel surface throughflow. Figure 7 also shows that most of these events in the channel throughflow are visible at a mooring (CAMP) $\sim 20 \mathrm{~km}$ southwest of $\mathrm{Pt}$. Arguello and a number of them also occur in sealevel at La Jolla. These latter reflect fluctuations in the flow at horizontal scales much larger than the channel.

\section{Acknowledgements}

This report summarizes an effort undertaken by several investigators. N.A. Bray is responsible for the development of the Data Zoo, the collection of historical observations that was used to design the current observation plan. C.E. Dorman is responsible for acquisition and analysis of meteorological observations. Guillermo Auad is analyzing the observations acquired in the course of the 1984 Minerals Management Service Study. Sabine Harms, Kari Richards, Ed Dever, Andrew Keyes, and Kate Edwards are analyzing the new observations. A.K. Münchow and W.M.L. Morawitz helped analyze the historical data set. David Browne, the COTR has provided continued intellectual support for the project. Support for this work is provided by Cooperative Agreement 14-35-0001-30571 between the Minerals Management Service and the University of California, San Diego.

\section{References}

Atkinson, L.P., K.H. Brink. R.E. Davis, B.H. Jones, T. Paluszkiewicz and D.W. Stuart, 1986: Mesoscale hydrographic variability in the vicinity of Pts. Conception and Arguello during April-May 1983: the OPUS 1983 Experiment. J. Geophys. Res., 91, 12,899-12,918.

Brink, K.H. and R.D. Muench. 1986: Circulation in the Pt.Conception-Santa Barbara Region. J. Geophys. Res., 91, 877-895.

D.W. Stuart and J.C. Van Leer, 1984: Observations of the Coastal Upwelling Region near $34^{\circ} 34^{\prime} \mathrm{N}$ off California: Spring 1981. J. Geophys. Res., 14, 378-391.

Davis, R.E., 1985: Drifter observations of coastal surface currents during CODE: the method and descriptive view. $J$. Geophys. Res.. 90, 4741-4755.

Dorman, C.E. and C.D. Winant, 1995: Buoy observations of the atmosphere along the west coast of the United States, 1981-1990. J. Geophys. Res., 100, 16,029-16,044.

Gunn, J.T., P. Hamilton, H.J. Herring, L.H. Kantha and G.S.E. Lagerloef, 1987: Santa Barbara Channel Circulation Model and Field Study, vols. 1 and 2. MMS 87-0089. Dynalysis of Princeton, Princeton, NJ. 393 pp.

Hamilton. P.. 1994: Long term monitoring of currents off Pt. Arguello, California. Eos, Trans., Amer. Geophys. Union, 75, 44/Supplement. 337.

Kolpack, R.J., 1971: Biological and Oceanographical Survey of the Santa Barbara Channel Oil Spill 1969-1970, Volume II, Ch. 4, Allan Hancock Foundation. Univ. of Southern Cal., 477 pp.

Lagerloef, G.S.E. and R.L. Bernstein. 1988: Empirical Orthogonal Function analysis of Advanced Very High Resolution Radiometer surface temperature patterns in Santa Barbara Channel. J. Geophys. Res., 93. 6863-6873.

Lynn, R.J. and J.J. Simpson. 1987: The California Current system: the seasonal variability of its physical characteristics. J. Geophys. Res., 92, 12,947-12,966.

Münchow, A.K., C.S. Coughran, M.C. Hendershott and C.D. Winant, 1995: Performance and calibration of an acoustic Doppler current profiler towed below the surface. J. Atmos. Ocean. Tech., 12, 435-444.

Reid, J.L., 1965: Physical oceanography of the region near Point Arguello. [La Jolla] Institute of Marine Resources. University of California, 1965, IMR Reference 65-19.

Sverdrup, H.U. and R.H. Fleming, 1941: The waters off the coast of southern California. March to July 1937. Scripps Institution of Oceanography Bulletin, 4, 261387.

Winant, C.D.. R.C. Beardsley and R.E. Davis, 1987: Moored Wind, Temperature and current observations made during Coastal Ocean Dynamics Experiments 1 and 2 over the northern California continental shelf and upper slope. J. Geophys. Res., 92, 1569-1603. 